\title{
Carbon balance and deuterium inventory from a carbon dominated to a full tungsten ASDEX Upgrade
}

\author{
M. Mayer ${ }^{a}$, V. Rohde $^{\text {a }}$, K. Sugiyama ${ }^{\text {a }}$, J.L. Chen ${ }^{a}$, X. Gong ${ }^{\text {a }}$, \\ C. Hopf ${ }^{\text {a }}$, J. Likonen ${ }^{\text {b }}$, S. Lindig ${ }^{\text {a }}$, R. Neu ${ }^{\text {a }}$, G. Ramos ${ }^{\text {c }}$, \\ E. Vainonen-Ahlgren ${ }^{\mathrm{b}}$, A. Wiltner ${ }^{\mathrm{a}}$, and ASDEX Upgrade Team \\ ${ }^{a}$ Max-Planck-Institut für Plasmaphysik, EURATOM Association, Boltzmannstr. 2, \\ D-85748 Garching, Germany \\ ${ }^{\mathrm{b}}$ VTT, Association EURATOM-Tekes, P.O. Box 1000, 02044 VTT, Finland \\ ${ }^{\mathrm{c}}$ CICATA-Qro, Instituto Politécnico Nacional, José Siurob 10, Col. Alameda, \\ 76040 Querétaro, México
}

\begin{abstract}
The evolution of carbon/boron deposition and the deuterium inventory were determined during the transition from a carbon dominated to a full tungsten ASDEX Upgrade. In the carbon dominated machine about $17 \mathrm{~g}$ of carbon were deposited at the inner divertor and in remote areas during one standard discharge campaign. Main carbon sources were the ICRH antennae protection limiters in the main chamber. After coating these limiters with tungsten the carbon deposition decreased to $3-5$ g. The remaining carbon originated mainly from erosion at the outer divertor strike point. Transition to a full tungsten machine resulted in a further decrease of the carbon deposition to about $1 \mathrm{~g} \cdot 1.3-1.7 \mathrm{~g}$ deuterium was trapped in codeposited carbon/boron layers in the divertor and in remote areas during the carbon dominated campaigns. The deuterium inventory decreased to $0.14-0.22 \mathrm{~g}$ in the full tungsten machine.
\end{abstract}

\section{Introduction}

With the decision of building ITER fusion research entered a new era. Integrated scenarios with both optimized plasma performance and compatibility with plasma-wall interactions phenomena gain increasing importance. ITER [1] follows a conservative approach by using beryllium for the main chamber plasma facing components (PFCs) and carbon fibre composites (CFCs) at the divertor strike points. This solution, however, may result in unacceptably 
high tritium inventories due to the high erosion yields of Be and $\mathrm{C}[2,3]$ and co-deposition with tritium [4-6]. In a future power reactor $\mathrm{Be}$ and $\mathrm{C}$ are not viable solutions and high-Z components will have to be used $[7,8]$.

A long term program was started in the divertor tokamak ASDEX Upgrade to implement tungsten PFCs and to explore their feasibility. The area of W-PFCs was increased steadily from 1999 to 2007, finally reaching a full-W machine [9]. The stepwise transition from a full carbon to a full tungsten machine offered the unique possibility to study the influence of the wall material on materials migration and deuterium inventory. The change of the wall material was therefore accompanied by an extensive surface analytical program [1014]. The influence of the wall material on plasma performance and impurity content can be found in [15], while this paper focuses on carbon migration and deuterium inventory.

\section{Experimental}

\subsection{Wall materials}

The replacement of carbon tiles by tungsten coated ones started in summer 1999, resulting in a full tungsten machine in the year 2007 [9]. The increasing W coverage is summarized in table 1, a graphical representation can be found in [16, Fig. 1]. The technical solution chosen was of $\mathrm{W}$ coatings on graphite and CFC [9]. Most tiles were coated with a $3-4 \mu \mathrm{m}$ thick W layer using physical vapor deposition (PVD), the outer strike point tiles were coated with $200 \mu \mathrm{m}$ $\mathrm{W}$ using vacuum plasma spraying (VPS).

A cross-section of the lower divertor is shown in Fig. 1. The inner divertor is formed by tiles 4 to $6 \mathrm{~B}$, tiles $9 \mathrm{~A}$ to $9 \mathrm{C}$ are the roof baffle, and tiles 10 to 3 the outer divertor. Tile 1 is the outer and tile 4 the inner strike point tile. All tiles consisted of fine grain graphite, except tile 4 which was made from carbon-fibre composite (CFC).

The inner heat shield and tiles $6 \mathrm{~A}$ and $6 \mathrm{~B}$ were already fully coated with tungsten during the 2002-2003 campaign. All upper divertor tiles, the protection tiles of the upper passive stabilizer loop (PSL), and outer baffle tiles 2, 3A and 3B were coated with tungsten before the $2004 / 2005$ campaign. The lower PSL protection tiles, all roof baffle tiles, the four ICRH antennae protection limiter frames (except the toroidal tile rows, which receive only little flux), and the auxiliary limiters in the main chamber were successively replaced by tungsten coated ones before the 2005/2006 campaign. This campaign therefore had a nearly full $\mathrm{W}$ main chamber, and important carbon areas were only remaining 
at the outer and inner divertor strike points. The strike point tiles were finally replaced by $\mathrm{W}$ coated ones before the 2007 campaign. This tile exchange was accompanied by a change of the geometry to divertor IIc: The substrate of tile 4 was changed from $\mathrm{CFC}$ to fine grain graphite and the tile got a flat shape, and tile 5 was slightly changed.

\subsection{Plasma operation and wall conditioning}

Important parameters of ASDEX Upgrade campaigns are listed in table 1. A typical campaign consists of 1000-1300 discharges with a total plasma time of 3000-5000 s. The campaigns 2005/2006 and 2007 were shorter due to the damage of a flywheel generator for power supply.

Usually $6-8$ boronizations using $\mathrm{B}_{2} \mathrm{D}_{6}$ are applied for wall conditioning. These deposit boron mainly in the main chamber and are almost ineffective in the divertor [17]. The $\mathrm{D}$ inventory introduced by boronizations is small compared to the gas introduced during plasma discharges [14]. The campaign 2002/2003 had one additional siliconization. Residual carbon and boron layers were removed before the 2007 full $\mathrm{W}$ campaign by wiping the walls with distilled water until the walls were metallic bright and no colored layers were visible any more. This imposes an upper boundary on the remaining thickness of a-B:H and a-C:H layers of about $10 \mathrm{~nm}$, because thicker layers are usually visible. No boronizations were performed during the 2007 campaign, and boron was hardly detectable by plasma spectroscopy [18].

\subsection{Analyzed samples and analysis methods}

Marker tiles coated with stripes of $250-600 \mathrm{~nm}$ W and $3 \mu \mathrm{m} \mathrm{C}$ on $200 \mathrm{~nm}$ Re were used for the determination of carbon erosion/deposition in the divertor [10,11]. A full poloidal set of tiles was used in the 2002/2003 and 2007 campaigns, while only sub-sets were used in 2004/2005 and 2005/2006. 20-35 long-term samples (LTS) were installed below the roof baffle and in other remote areas in order to measure the carbon deposition and deuterium retention in remote areas $[19,12,14]$.

Marker layers were analyzed prior to installation with Rutherford-backscattering (RBS) using high energy protons. The tiles were analyzed again after exposure using RBS under the same conditions, thus providing information about the change of the marker layer thickness and material deposition on the marker $[10,11]$. Deuterium was detected by nuclear reaction analysis (NRA) using the $\mathrm{D}\left({ }^{3} \mathrm{He}, \mathrm{p}\right){ }^{4} \mathrm{He}$ reaction at different incident energies [14]. NRA was also applied for detection of $\mathrm{C}$ using the ${ }^{12} \mathrm{C}\left({ }^{3} \mathrm{He}, \mathrm{p}_{1}\right){ }^{14} \mathrm{~N}$ reaction at $2500 \mathrm{keV}$ incident en- 
ergy. Secondary ion mass spectroscopy (SIMS) depth profiling was made with $5 \mathrm{keV} \mathrm{O}_{2}$ ions. TDS measurements were performed in the TESS device [20] with samples of $10 \times 20 \times 2 \mathrm{~mm}^{3}$ cut from divertor tiles. The samples were heated to $1200 \mathrm{~K}$ with a heating ramp of $0.5 \mathrm{~K} / \mathrm{s}$, and masses $3 \mathrm{amu}$ (HD), $4 \mathrm{amu}\left(\mathrm{D}_{2}\right)$, and $20 \mathrm{amu}\left(\mathrm{CD}_{4}\right)$ were recorded with a quadrupole mass spectrometer (QMS).

\section{Results}

\subsection{Evolution of $C$ deposition and $D$ inventory}

Almost the whole outer divertor is a net erosion area for $\mathrm{C}$ and $\mathrm{W}[10,11]$. A small deposition area was observed below the outer strike point (on the lowest $2-5 \mathrm{~cm}$ of tile $1 \mathrm{~A}$ ) after all campaigns, the amount of $\mathrm{B}+\mathrm{C}$ deposited in this area is shown in Fig. 3 as triangle. Some additional deposition areas in close vicinity to erosion areas were observed after the 2002/2003 campaign, but these were difficult to quantify due to partial delamination of the marker strike. This results in a large error bar, see Fig. 3. The amount of $\mathrm{C}$ was determined by NRA after the 2007 campaign within the top $0.6 \mu \mathrm{m}$. The measured amount marks an upper limit for the amount of redeposited carbon, because $\mathrm{C}$ impurities in the original $\mathrm{W}$ layers are accounted as well. Generally the amounts of codeposited $\mathrm{D}$ and $\mathrm{C}$ in the outer divertor are much smaller than in the inner one [14].

The distributions of $\mathrm{B}, \mathrm{C}$ and $\mathrm{D}$ in the inner divertor are shown in Fig. 2, total amounts of these elements (normalized to a 'standard campaign' with $3000 \mathrm{~s}$ discharge time) are shown in Fig. 3. The s-coordinate used in Fig. 2 starts at the upper corner of tile $6 \mathrm{~A}$ and follows the tile surfaces. Tile numbers are indicated in Fig. 2. The inner strike point distribution is shown in Fig. 2 for the 2002/2003 and 2007 campaigns, the distribution for other campaigns was comparable. The inner strike point was normally on tile 4, with only a few discharges having the strike point on the roof baffle. After the 2002/2003 campaign, the thickest deposits are observed at tile 4, but thick deposits are also observed on tiles 5 and $6 \mathrm{~B}$. The deposits consist mainly of $\mathrm{C}$ with about $20 \%$ of $\mathrm{B}$, while $\mathrm{D}$ is co-deposited with $\mathrm{B}$ and $\mathrm{C}$ at a ratio $\mathrm{D} /(\mathrm{B}+\mathrm{C})$ from 0.2 to 0.5 . SIMS depth profiles are in good agreement with the NRA results. The $\mathrm{D}$ inventory and the $\mathrm{D} /(\mathrm{B}+\mathrm{C})$ ratio was lower on tile 5 than on adjacent tiles during the 2002/2003 campaign. This lower amount of D on tile 5 was not reproduced during the 2004/2005 campaign, where all investigated tiles showed $\mathrm{D}$ inventories close to $\mathrm{D} /(\mathrm{B}+\mathrm{C})=0.4$. An upper boundary for the possible $\mathrm{D}$ inventory can be obtained from the amount of $\mathrm{B}+\mathrm{C}$ and the assumption $\mathrm{D} /(\mathrm{B}+\mathrm{C})=0.4$. This is marked by the dashed line in Fig. 2 and is also the 
upper end of the error bar in Fig. 3 .

After the $2004 / 2005$ campaign the amount of $\mathrm{B}+\mathrm{C}$ on tiles $6 \mathrm{~A}, 6 \mathrm{~B}$ and 5 was comparable to $2002 / 2003$, and $\mathrm{D}$ was observed at a ratio of $\mathrm{D} /(\mathrm{B}+\mathrm{C}) \approx 0.4$ on all tiles. For extrapolation to the whole inner divertor the same ratio of deposition on tiles $(4+9 \mathrm{C}) /(6 \mathrm{~A}+6 \mathrm{~B}+5)$ as in $2002 / 2003$ was assumed. The uncertainty of this extrapolation is taken into account by the error bars in Fig. 3. The amounts of deposited D, B and C were identical to the 2002/2003 campaign within the error bars despite the increase of the $\mathrm{W}$ coverage by a factor of almost two, see table 1.

During the 2005/2006 campaign a thick W marker stripe was used for detection of deposited $\mathrm{B}$ and $\mathrm{C}$. The extrapolation to the whole inner divertor was done in the same way as after the 2004/2005 campaign, see above. The determined amounts of deposited $\mathrm{B}$ and $\mathrm{C}$ in this campaign are probably somewhat too low, as can be cross-checked with the amounts of D: The W marker was too thick, which made the detection of $\mathrm{B}$ and $\mathrm{C}$ difficult. This is taken into account by the asymmetric error bar in Fig. 3, where the upper end is obtained from the amount of $\mathrm{D}$ and the assumption of $\mathrm{D} /(\mathrm{B}+\mathrm{C})=0.4$. The amount of deposited $\mathrm{C}$ decreased by a factor of 4-6 in this campaign, as compared to the two earlier ones, while the amount of deposited $\mathrm{B}$ remained identical within the error bars. This is reasonable, because the number of boronizations was comparable to the campaigns before, see Table 1 . The amount of codeposited $\mathrm{D}$ decreased by a factor of about two. This smaller decrease of $\mathrm{D}$ compared to $\mathrm{C}$ is due to codeposition with $\mathrm{B}$.

The amount of deposited $\mathrm{C}$ decreased by another factor of 2-4 in 2007 with the full $\mathrm{W}$ machine, and the deposition pattern showed a qualitative change: While carbon was mainly deposited in the strike point area of tile 4 and the adjacent tile 5 in the carbon dominated machine, in the full $\mathrm{W}$ machine carbon is mainly deposited below the inner strike point. The strike point area of tile 4 , and the whole tile 5 , show only very small residual carbon deposits. There were no boronizations in the 2007 campaign. Some B was visible on the divertor tiles by RBS, but the amount was too small for quantification. The amount of $\mathrm{B}$ was below the detection limit of about $0.08 \mathrm{~g}$. Boron originates from residual boron layers on main chamber tiles created during boronizations in previous campaigns, which are then eroded. The small deposition of B in the divertor indicates that the performed cleaning procedure of main chamber tiles was successful, and left behind only small amounts of remaining B.

A decreasing carbon and deuterium codeposition was also observed in remote areas, see Fig. 3. The largest decrease was observed after coating the outer baffle with W before the 2004/2005 campaign.

The evolution of carbon deposition allows the following conclusions: 
- At least $17 \mathrm{~g}$ carbon were deposited in the inner and outer divertors and in remote areas during one campaign with the carbon dominated machine.

- Coating the ICRF protection limiter frames with W resulted in a drop of the inner divertor carbon deposition by a factor of 4-6 from 2004/2005 to $2005 / 2006$. This points toward these limiters to have been the major carbon source in ASDEX Upgrade, from where 12-15 g C were eroded and transported to the inner divertor.

- The campaign $2005 / 2006$ was characterized by a full tungsten main chamber wall and carbon divertor strike points. The observed deposition of $3-5 \mathrm{~g} \mathrm{C}$ can be explained by the measured erosion of about $3 \mathrm{~g} \mathrm{C}$ in the outer divertor [11]: Migration of carbon from the outer divertor to the main chamber was observed spectroscopically [21]. Carbon may then recycle at the main chamber walls and may be subsequently transported to the inner divertor, where it is finally redeposited. Some fraction of this carbon may be redeposited in the main chamber (at side faces of limiters, tile gaps etc.), but the small contribution of the main chamber to the total D inventory [14] indicates that this fraction is small.

- The residual carbon deposition in the full $\mathrm{W}$ machine is about $1 \mathrm{~g}$. Remaining carbon sources are discussed below.

\subsection{Carbon sources in the full $W$ machine}

The carbon deposition decreased by a factor of at least 15 from the carbon dominated machine 2002/2003 to the full W machine. This decrease of deposited carbon was accompanied by a decrease of the carbon plasma concentration, but only by a factor of $2-3[18,22]$. This can be probably explained by the small amounts of carbon present in the plasma, which can be sustained even by small carbon influxes, or by a change of carbon recycling.

Where are remaining carbon sources in the full $\mathrm{W}$ machine?

- Carbon on tungsten coatings: Carbon was deposited on the tungsten coatings during previous, more carbon-rich campaigns. This carbon can be subsequently eroded and transported to the divertor. However, this amount is assumed to be small due to the extensive cleaning of the vessel before the 2007 campaign. This assumption is supported by the very small amount of deposited boron, which also originates from layers deposited during previous campaigns.

- Erosion of carbon tiles by hydrogen: Atomic hydrogen is able to survive several wall collision and may penetrate into tile gaps and to the back side of tiles. These areas are not completely coated with $\mathrm{W}$, and carbon can be eroded by chemical erosion with thermal hydrogen atoms. This erosion is difficult to quantify, but is expected to be small due to the small erosion 
yield by atomic hydrogen at room temperature, which is $<2 \times 10^{-4}[23,24]$.

- Erosion of carbon tiles by oxygen: Oxygen may erode carbon in tile gaps and at back side of tiles by formation of $\mathrm{CO}$ and $\mathrm{CO}_{2}$. These gases became the main components of the residual gas between discharges in the full $\mathrm{W}$ ASDEX Upgrade.

- Electrical arcs: Many arc tracks are observed on tiles in the inner baffle on tiles $6 \mathrm{~A}, 6 \mathrm{~B}$ and some areas of tile 5 [25]. The $\mathrm{W}$ coating can be fully removed in the arc track, and the underlying carbon is eroded by the arc.

- Carbon impurities in $W$ coatings: The carbon content of the PVD-W layers is about $2 \%$. Erosion of $\mathrm{W}$ coatings is therefore always accompanied by $\mathrm{C}$ release due to erosion.

- Photodesorption of $\mathrm{CO}$ and $\mathrm{CO}_{2}$ : $\mathrm{CO}$ and $\mathrm{CO}_{2}$, which are adsorbed at metallic vessel walls from the residual gas, are released during plasma discharges by photodesorption [26]. $\mathrm{CO}$ and $\mathrm{CO}_{2}$ may originate from erosion of carbon by oxygen, or from the residual gas.

\subsection{Deuterium inventory}

In the carbon dominated machine $1.3-1.7 \mathrm{~g} \mathrm{D}$ was trapped in the ASDEX Upgrade divertor and in remote areas during $3000 \mathrm{~s}$ plasma operation (fig. 3). Other areas, such as tile gaps, upper divertor, limiter tiles etc. add an additional $0.1-0.2 \mathrm{~g} \mathrm{[14]}$ and are not considered in the following. D was mainly retained due to codeposition with $\mathrm{C}$, and to some extend also by codeposition with B. A reduction of the carbon deposition by a factor of 4-6 in the $2005 / 2006$ campaign reduced the $\mathrm{D}$ inventory only by a factor of less than 2 due to the remaining codeposition with $\mathrm{B}$ in the inner divertor by regular boronizations. Absence of boronizations and a further reduction of the $\mathrm{C}$ deposition in the full $\mathrm{W}$ machine finally reduced the D inventory to $0.14-0.22 \mathrm{~g}$. The inventory in the inner divertor appears to be still dominated by codeposition with remaining $\mathrm{C}$, as can be seen by the correlation between $\mathrm{D}$ and C (Fig. 2). This was confirmed by deuterium depth profiles from the area of highest inventory on tile 4 , which showed that $\mathrm{D}$ was trapped in $\mathrm{C}$ layers on top of the W. But the total D-inventory was now dominated by the outer divertor, see Figs. 3 and 4 . The outer divertor showed only small amounts of redeposited $\mathrm{C}$ and the amount of $\mathrm{D}$ exceeded the amount of $\mathrm{C}$ (see Fig. 4), which already indicates that the majority of $\mathrm{D}$ was trapped in $\mathrm{W}$. This is confirmed by the larger amount of detected D by TDS than by NRA within the top $3 \mu \mathrm{m}$. Although some codeposition with $\mathrm{C}$ may have occurred, especially in pores and valleys of the very rough VPS layers on the outer strike point tile 1 , the total D inventory is now dominated by implantation, diffusion and trapping in the $200 \mu \mathrm{m}$ thick VPS layers at the outer strike point. The dip in the D-inventory on tile 1 (see Fig. 4) is observed at the most often used strike point position, where also the highest power fluxes and surface temperatures 
are observed.

As was already shown in [27], VPS layers trap about 5 times more D than polycrystalline $\mathrm{W}$ at low fluences, while the amounts of trapped D get identical at higher fluences for both materials. This was confirmed for the ASDEX Upgrade conditions by determining the D inventory in polycrystalline $\mathrm{W}$ samples from flash-mounted Langmuir probes at the outer strike point, which were exposed under identical conditions as the VPS layer and gave identical amounts of trapped D in TDS measurements [28]. This indicates that a bulk W divertor would retain about the same amount of D as the used VPS layers.

\section{Conclusions}

The stepwise transition from a full carbon to a full tungsten machine allowed to identify the main carbon sources in ASDEX Upgrade. About $17 \mathrm{~g}$ carbon were deposited in the divertor and in remote areas during one 'standard' campaign (3000 s discharge time) in the carbon dominated machine. 12-15 g of this deposited carbon originated from the ICRF protection limiter frames in the main chamber, and 3-5 g from the outer divertor. The replacement of all carbon tiles by $\mathrm{W}$ coated ones reduced the divertor carbon deposition to about $1 \mathrm{~g}$. Some fraction of this residual carbon deposition originates from the applied technical solution, i.e. tungsten layers on carbon tiles, which allows the release of carbon by electrical arcs (which can erode the whole $\mathrm{W}$ layer in the arc track) and by chemical erosion of $\mathrm{C}$ by atomic hydrogen or oxygen in tile gaps and at tile back sides.

In the carbon dominated machine D was trapped in codeposited boron/carbon layers mainly in the inner divertor and, to a lesser extent, in codeposited carbon layers in remote areas. A reduction of the carbon deposition by a factor of 4-6 resulted in a reduction of the D inventory only by a factor of 2 due to continuing boronization and codeposition with $\mathrm{B}$. The transition to a full $\mathrm{W}$ machine without boronizations finally reduced the trapped D inventory by a factor of 5-10, as compared to the carbon dominated machine. Although this reduction is already encouraging from the viewpoint of tritium inventory, it does not yet mark the full potential of tungsten for long pulse machines: The amount of hydrogen trapped by codeposition with carbon increases linearly with particle fluence (or discharge time), while the amount of hydrogen trapped in tungsten increases only with the square root of fluence [29,30]. This results in even smaller inventories for all-tungsten compared to all-carbon machines at high fluences and makes tungsten even more favorable for long pulse or steady-state machines. The ASDEX Upgrade results are in good agreement with laboratory measurements. Identical deuterium inventories in the plasma-sprayed $200 \mu \mathrm{m}$ thick W-layers and bulk W are observed. A full tung- 
sten machine therefore could be a viable solution for the problem of tritium inventory in ITER and DEMO.

\section{Acknowledgements}

Ion beam analysis measurements by T. Utikal, F. Blobner, B. Tyburska and H. Kulinski, and the technical assistance by J. Dorner and M. Fußeder are gratefully acknowledged.

\section{References}

[1] R. Aymar, P. Barabaschi, and Y. Shimomura. Plasma Phys. Controlled Fusion 44 (2002) 519.

[2] E. Vietzke and A.A. Haasz. Chemical erosion. In Physics of Plasma-Wall Interactions in Controlled Fusion, W. Hofer and J. Roth, Eds. Academic Press, San Diego, New York, Boston, London, Sydney, Tokyo, Toronto, 1996, p. 135.

[3] M. Balden and J. Roth. J. Nucl. Mater. 280 (2000) 39.

[4] M. Mayer, V. Philipps, P. Wienhold, H.G. Esser, J. von Seggern, and M. Rubel. J. Nucl. Mater. 290-293 (2001) 381.

[5] G. Federici, R. Anderl, P. Andrew, J.N. Brooks, R.A. Causey, J.P. Coad, D. Cowgill, R.P. Doerner, A.A. Haasz, G. Janeschitz, W. Jacob, G.R. Longhurst, R. Nygren, A. Peacock, M.A. Pick, V. Philipps, J. Roth, C.H. Skinner, and W.R. Wampler. J. Nucl. Mater. 266-269 (1999) 14.

[6] G. Federici, J.N. Brooks, D.P. Coster, G. Janeschitz, A. Kukuskhin, A. Loarte, H.D. Pacher, J. Stober, and C.H. Wu. J. Nucl. Mater. 290-293 (2001) 260.

[7] G. Janeschitz, P. Barabaschi, G. Federici, K. Ioki, P. Ladd, V. Mukhovatov, M. Sugihara, R. Tivey, and ITER-JCT and Home Team. Nucl. Fusion 40 (2000) 1197.

[8] H. Bolt, V. Barabash, W. Krauss, J. Linke, R. Neu, S. Suzuki, N. Yoshida, and ASDEX Upgrade Team. J. Nucl. Mater. 329-333 (2004) 66.

[9] R. Neu, V. Bobkov, R. Dux, A. Kallenbach, Th. Pütterich, H. Greuner, O. Gruber, A. Herrmann, Ch. Hopf, K. Krieger, C.F. Maggi, H. Maier, M. Mayer, V. Rohde, K. Schmid, W. Suttrop, and ASDEX Upgrade team. J. Nucl. Mater. 363-365 (2007) 52.

[10] M. Mayer, V. Rohde, J. Likonen, E. Vainonen-Ahlgren, K. Krieger, X. Gong, J. Chen, and ASDEX Upgrade Team. J. Nucl. Mater. 337-339 (2005) 119. 
[11] M. Mayer, V. Rohde, G. Ramos, E. Vainonen-Ahlgren, J. Likonen, J.L. Chen, and ASDEX Upgrade team. Physica Scripta T128 (2007) 106.

[12] M. Mayer, V. Rohde, A. von Keudell, and the ASDEX Upgrade Team. J. Nucl. Mater. 313-316 (2003) 429.

[13] M. Mayer, V. Rohde, and ASDEX Upgrade Team. Nucl. Fusion 46 (2006) 914.

[14] M. Mayer, V. Rohde, G. Ramos, E. Vainonen-Ahlgren, J. Likonen, A. Herrmann, R. Neu, and the ASDEX Upgrade Team. Nucl. Fusion 47 (2007) 1607.

[15] R. Dux, V.Bobkov, A. Herrmann, A. Janzer, A. Kallenbach, R. Neu, M. Mayer, H.W. Mueller, R. Pugno, T. Pütterich, V. Rohde, and A.C.C. Sips. J. Nucl. Mater. (2009) . submitted, presented at PSI-18.

[16] R. Neu, Ch. Hopf, A. Kallenbach, T. Pütterich, R. Dux, H. Greuner, O. Gruber, A. Herrmann, K. Krieger, H. Maier, V. Rohde, and ASDEX Upgrade Team. J. Nucl. Mater. 367-370 (2007) 1497.

[17] V. Rohde, R. Neu, R. Dux, T. Härtl, H. Maier, J. Luthin, H.G. Esser, V. Philipps, and ASDEX Upgrade Team. Comparison of boronization and siliconization in ASDEX Upgrade. In 26th EPS Conference on Controlled Fusion and Plasma Physics (1999), vol. 23J of europhysics conference abstracts, p. 1513.

[18] A. Kallenbach, R. Dux, M. Mayer, R. Neu, T. Pütterich, V. Bobkov, J.C. Fuchs, T. Eich, O. Gruber, A. Herrmann, C.F. Maggi, H. Meister, R. Pugno, V. Rohde, A. Sips, A. Stäbler, J. Stober, and ASDEX Upgrade Team. Non-boronized operation of ASDEX Upgrade with full-tungsten plasma facing components. In Proceedings of the 22nd Fusion Energy Conference (2008), IAEA, pp. EX/9-2.

[19] V. Rohde, H. Maier, K. Krieger, R. Neu, J. Perchermaier, and ASDEX Upgrade Team. J. Nucl. Mater. 290-293 (2001) 317.

[20] E. Salançon, T. Dürbeck, T. Schwarz-Selinger, F. Genoese, and W. Jacob. J. Nucl. Mater. 376 (2008) 160.

[21] A. Kallenbach, R. Dux, J. Harhausen, C.F. Maggi, R. Neu, T. Pütterich, V. Rohde, K.Schmid, E. Wolfrum, and the ASDEX Upgrade Team. J. Nucl. Mater. 363-365 (2007) 60.

[22] R. Pugno and ASDEX Upgrade Team. In 35th EPS Conference on Controlled Fusion and Plasma Physics (2008), europhysics conference abstracts.

[23] E. Vietzke, V. Philipps, K. Flaskamp, P. Koidl, and Ch. Wild. Surf. Coat. Technol. 47 (1991) 156.

[24] M. Schlüter, C. Hopf, T. Schwarz-Selinger, and W. Jacob. J. Nucl. Mater. 376 (2008) 33.

[25] A. Herrmann, M. Balden, M. Laux, K. Krieger, H.W. Müller, R. Pugno, V. Rohde, and ASDEX Upgrade team. J. Nucl. Mater. (2009) . in print, presented at PSI-18. 
[26] V. Philipps, E. Vietzke, M. Erdweg, and J. Winter. J. Nucl. Mater. 200 (1993) 355.

[27] A.V. Golubeva, V.A. Kurnaev, M. Mayer, and J.Roth. Hydrogen retention in plasma-sprayed tungsten. In Hydrogen in Matter: A Collection from the Papers Presented at the 2nd International Symposium on Hydrogen in Matter; ISOHIM (2006), vol. 837 of AIP Conference Proceedings, American Insitute of Physics.

[28] K. Sugiyama, M. Mayer, V. Rohde, R. Neu, T. Höschen, M. Balden, S. Lindig, H.W. Müller, and ASDEX Upgrade team. Deuterium inventory in the full tungsten divertor of ASDEX Upgrade. presented at the 9th International Workshop on Hydrogen Isotopes in Fusion Reactor Materials, Salamanca, Spain. June 2-3, 2008. To be published.

[29] O.V. Ogorodnikova, J. Roth, and M. Mayer. J. Nucl. Mater. 313-316 (2003) 469.

[30] O.V. Ogorodnikova, J. Roth, and M. Mayer. J. Appl. Phys. 103 (2008) 034902. 
Table 1

ASDEX Upgrade tungsten wall area and plasma operation for the campaigns 20022007. The campaign 2007 is with $100 \%$ tungsten wall coverage. Campaigns between 2002 and 2005 had a 1 week hydrogen operation phase at their end.

\begin{tabular}{lcccccc}
\hline Campaign & from - to & $\begin{array}{c}\text { W area } \\
{\left[\mathrm{m}^{2}\right]}\end{array}$ & $\begin{array}{c}\text { Number } \\
\text { of } \\
\text { discharges }\end{array}$ & $\begin{array}{c}\text { Plasma } \\
\text { time } \\
{[\mathrm{s}]}\end{array}$ & $\begin{array}{c}\text { Number } \\
\text { of } \\
\text { boronizations }\end{array}$ & $\begin{array}{c}\text { Hydrogen } \\
\text { phase }\end{array}$ \\
\hline $2002 / 2003$ & $11 / 2002-8 / 2003$ & 14.6 & 1237 & 4856 & 6 & Yes \\
$2003 / 2004$ & $12 / 2003-8 / 2004$ & 24.8 & 1284 & 4131 & 8 & Yes \\
$2004 / 2005$ & $11 / 2004-7 / 2005$ & 28.0 & 1099 & 3864 & 6 & Yes \\
$2005 / 2006$ & $12 / 2005-4 / 2006$ & 35.9 & 727 & 2950 & 5 & No \\
2007 & $5 / 2007-10 / 2007$ & 42.2 & 976 & 2620 & 0 & No \\
\hline
\end{tabular}




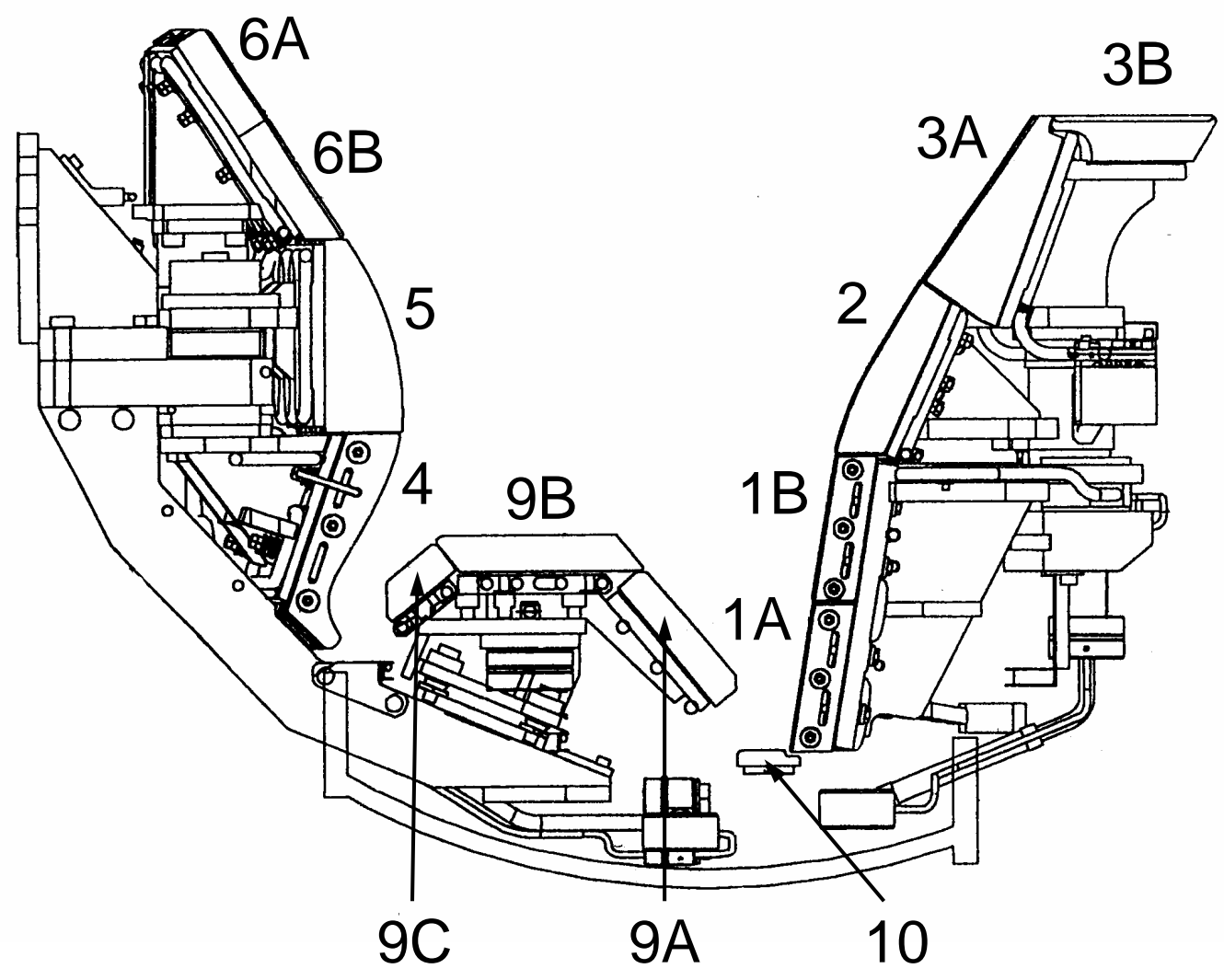

Fig. 1. Layout of ASDEX Upgrade divertor IIb, which was used during the discharge campaigns 2002-2006. Numbers indicate tile numbers, as used throughout this paper. 

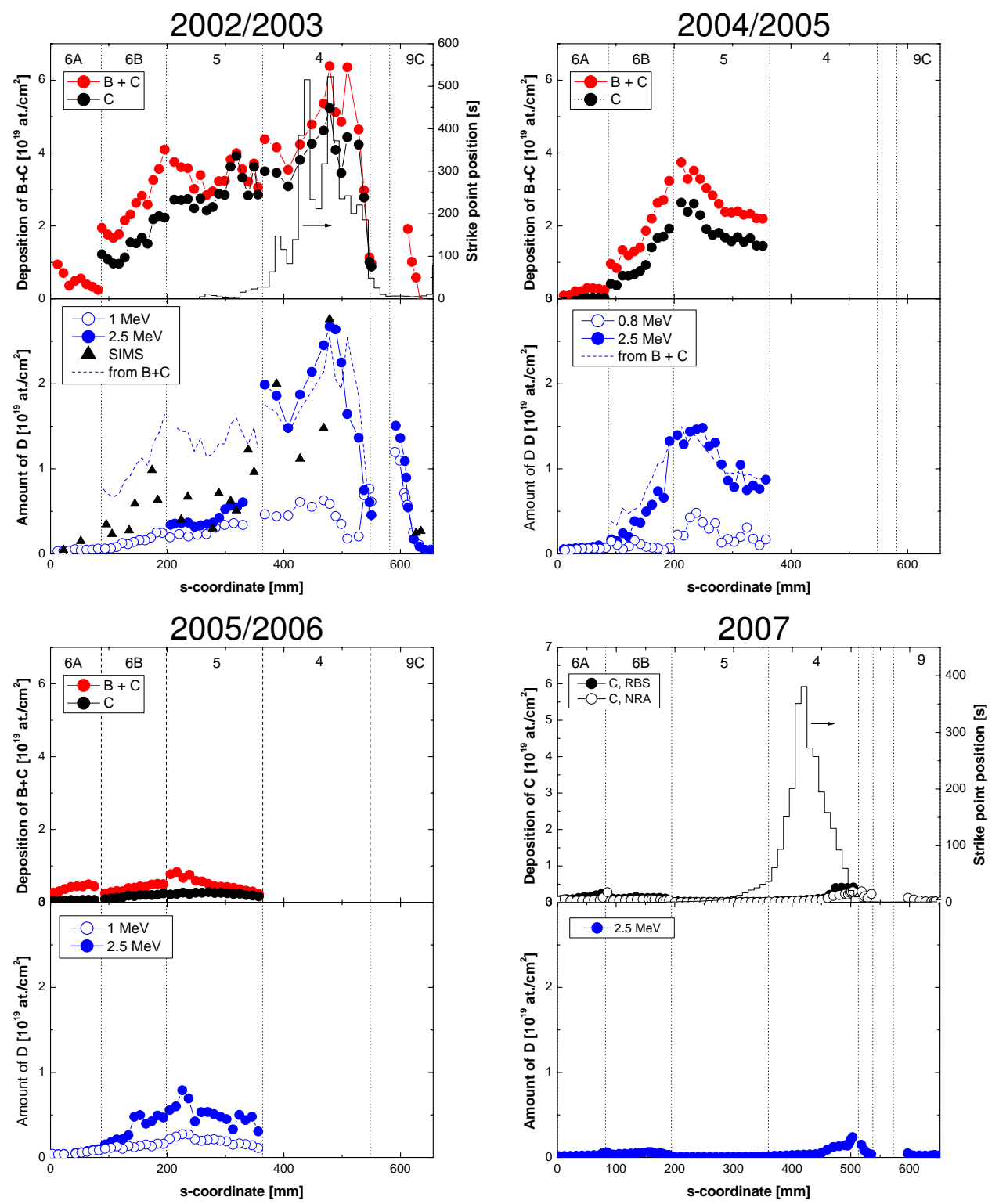

Fig. 2. Deposition of $\mathrm{B}$ and $\mathrm{C}$ and deuterium inventory in the inner divertor of ASDEX Upgrade. Upper half of each panel: Amounts of B and C, determined by RBS. In 2007 the amount of $\mathrm{C}$ was determined by RBS and NRA, while $\mathrm{B}$ was below the detection limit. Histograms: Inner strike point positions in the $2002 / 2003$ and 2007 campaigns. Lower half of each panel: Dots: Amount of D, determined by NRA at 2 different energies. Triangles: Amount of $\mathrm{D}$, determined by SIMS. Dashed lines: Deuterium inventory derived from the amount of $(B+C)$ assuming $D /(B+C)=$ 0.4 . 


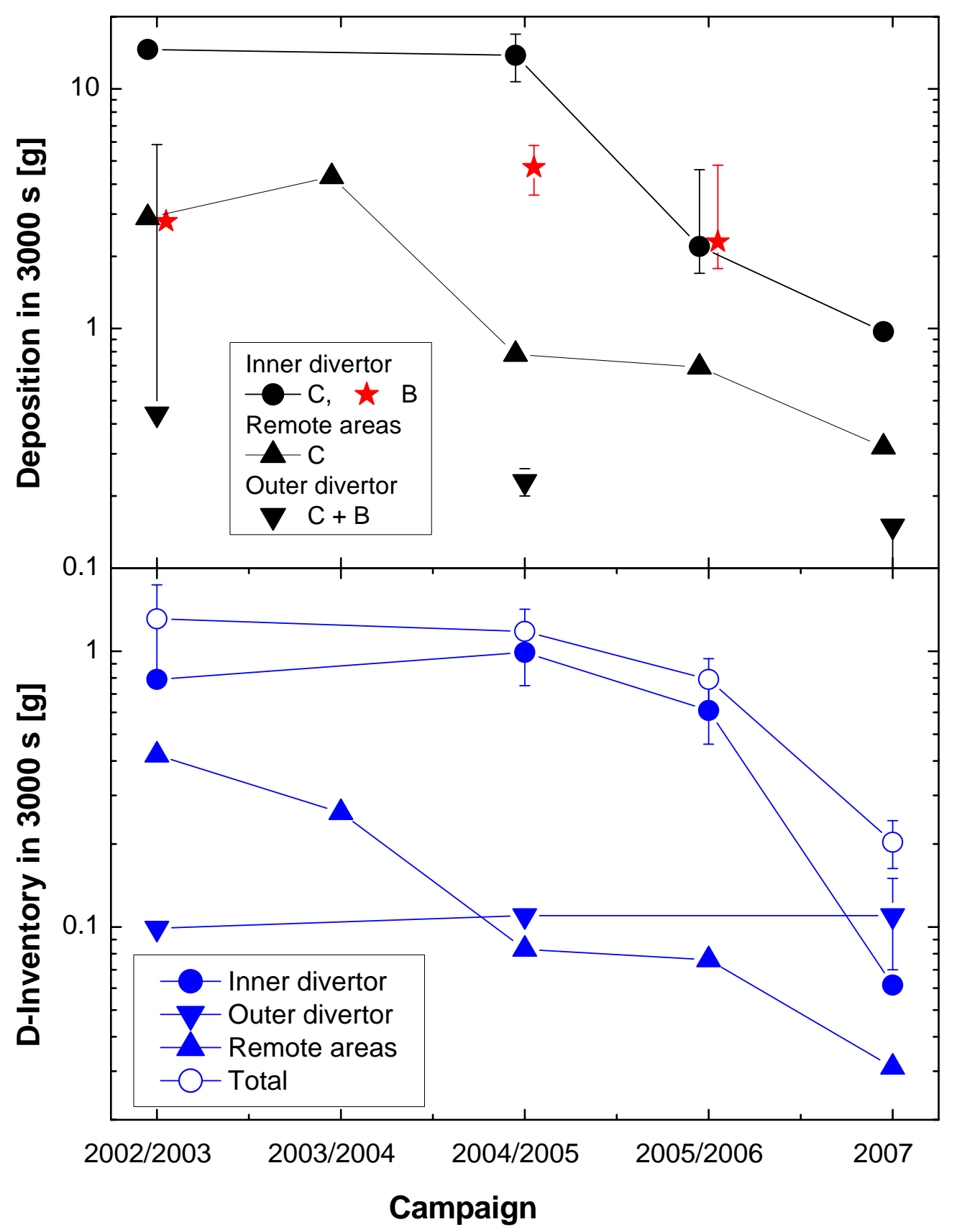

Fig. 3. Deposition of B and C (top) and deuterium inventory (bottom) in the divertor and in remote areas of ASDEX Upgrade from 2002 to 2007. The error bars take systematic errors into account (see text). The amount of B was below the detection limit of $0.08 \mathrm{~g}$ in 2007. 


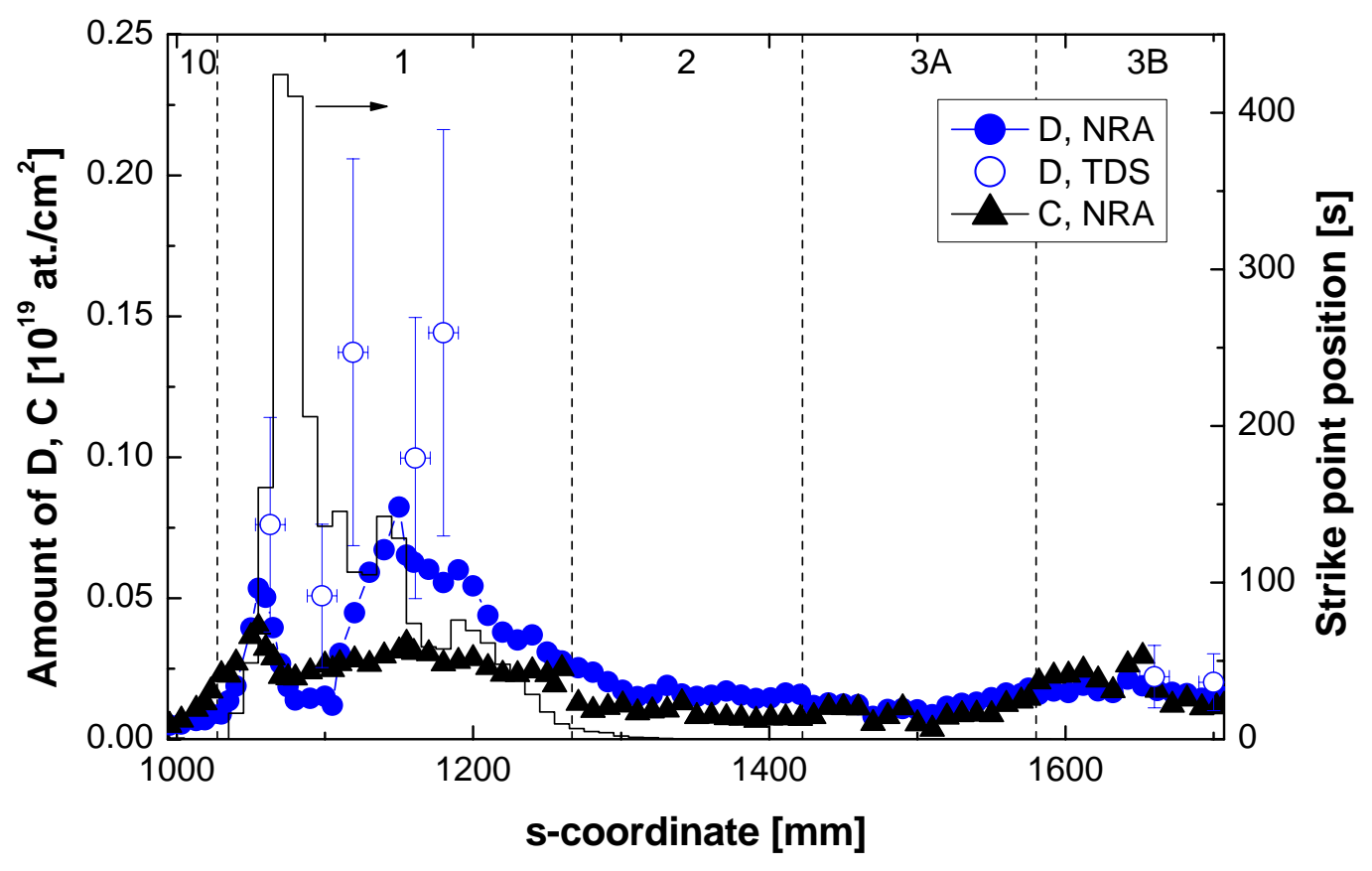

Fig. 4. Solid triangles and dots: Carbon deposition and deuterium inventory in the outer divertor after the 2007 campaign, measured by NRA with $2500 \mathrm{keV}^{3} \mathrm{He}$ having information depths of about $3 \mu \mathrm{m}$ for $\mathrm{D}$ and about $0.6 \mu \mathrm{m}$ for C. Open dots: Deuterium inventory determined by TDS. Histogram: Distribution of strike point positions. Tile numbers are indicated at the top. 